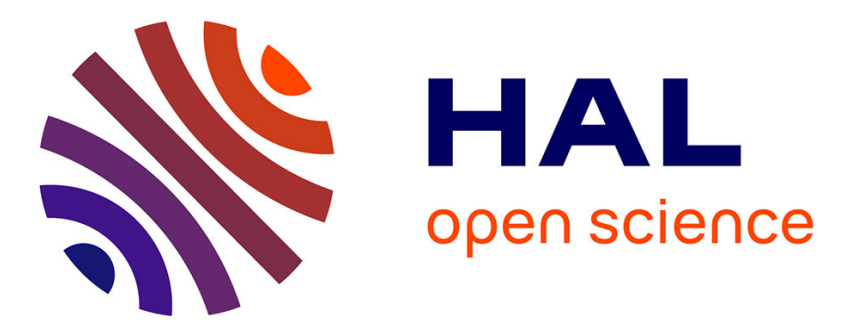

\title{
A modeling and optimization framework for power system design with operational flexibility and resilience against extreme weather events
}

Islam Abdin, Y.-P. Fang, Enrico Zio

\section{- To cite this version:}

Islam Abdin, Y.-P. Fang, Enrico Zio. A modeling and optimization framework for power system design with operational flexibility and resilience against extreme weather events. Renewable and Sustainable Energy Reviews, 2019, 112, pp.706-719. 10.1016/j.rser.2019.06.006 . hal-02428603

\section{HAL Id: hal-02428603 \\ https://hal.science/hal-02428603}

Submitted on 6 Jan 2020

HAL is a multi-disciplinary open access archive for the deposit and dissemination of scientific research documents, whether they are published or not. The documents may come from teaching and research institutions in France or abroad, or from public or private research centers.
L'archive ouverte pluridisciplinaire HAL, est destinée au dépôt et à la diffusion de documents scientifiques de niveau recherche, publiés ou non, émanant des établissements d'enseignement et de recherche français ou étrangers, des laboratoires publics ou privés. 


\title{
A modeling and optimization framework for power system design with operational flexibility and resilience against extreme weather events
}

\author{
Abdin, I.F.a , Fang, Y.-P. ${ }^{\text {, }, ~ Z i o, ~ E . ~}$,c,* $^{\text {, }}$ \\ ${ }^{a}$ Laboratoire Genie Industriel, CentraleSupélec, Université Paris-Saclay \\ 3 Rue Joliot Curie, 91190 Gif-sur-Yvette, France. \\ Chair Systems Science and the Energy Challenge, Fondation Electricité de France (EDF) \\ ${ }^{b}$ Mines ParisTech, PSL Research University, CRC, Sophia Antipolis, France \\ ${ }^{c}$ Department of Energy, Politecnico di Milano, Italy
}

\begin{abstract}
Operational flexibility is an integral part of the design of power systems with a high share of renewable energy sources. Resilience against severe weather is also becoming an important concern. In this paper, we propose a comprehensive framework for power systems planning which considers both flexibility and resilience against extreme weather events. A set of piece-wise linear models are developed to calculate the impact of extreme heat waves and drought events on the performance of the power generation units and on the system load. We analyze the results obtained on a case study under real future climate projections from the Coupled Model Intercomparison Project phase 5 and compare them to those from conventional planning methods.
\end{abstract}

\section{Highlights}

- A quantitative modeling framework for extreme heat wave and drought events

- An optimization model for resilient power system design against extreme weather impact

\footnotetext{
* Corresponding author

Email addresses: islam.abdin@centralesupelec.fr (Abdin, I.F.), yiping.fang@centralesupelec.fr (Fang, Y.-P.), enrico.zio@polimi.it (Zio, E.)
} 
- High shares of renewables improve the system resilience against extreme heat wave events

- Investigation of the interaction between the flexibility and resilience of power systems

\section{Keywords}

Power system design; renewable energy penetration; operational flexibility; extreme weather events; power system resilience

\section{Word Count}

7000 words

\section{Declarations of interest}

None 


\section{Nomenclature}

Abbreviations

CF Capacity Factor

CLC Closed-Loop Cooling

CMIP5 Coupled Model Intercomparison Project phase 5

CP Conventional Planning

EAC Equivalent Annual Cost

EFS Expected Flexibility Shortfall

HUA Hourly Unit Availability

IGEP Integrated Generation Expansion Planning

IRES Intermittent Renewable Energy Sources

LNS Load Not Served

MILP Mixed Integer Linear Programming

O\&M Operation and Maintenance

OTC Once-Through Cooling

PV Photo Voltaic

RCP Representative Concentration Pathway

RP Resilient Planning

VaR Value at Risk

Indexes:

$i \quad$ index of power plant cluster

$j$ index of sub-periods (hours)

$w$ index of sub-periods (weeks)

$y \quad$ index of planning year 
Sets:

I set of power plant per technologies

$I^{\text {new }}$ subset of new power plants technologies available

$I^{\text {res }} \quad$ subset of renewable energy units

$I^{\text {th }} \quad$ subset of thermal and nuclear units

$T \quad$ set of hourly sub-periods

$W \quad$ set of weekly sub-periods

$Y \quad$ set of years in the planning horizon 
Parameters:

\begin{tabular}{|c|c|}
\hline$C_{i}^{i n v}$ & investment cost of unit $i(\mathrm{M} €)$ \\
\hline$C^{l n s}$ & cost of load not served $(€ /$ MWh $)$ \\
\hline$C_{i, y}^{\text {marg }}$ & $\begin{array}{l}\text { marginal cost of power plant } i \text { including the variable } \mathrm{O} \& \mathrm{M} \text { and } \mathrm{CO}_{2} \text { costs, con- } \\
\text { sidering inflation }(€ / \mathrm{MWh})\end{array}$ \\
\hline$C_{i}^{O M}$ & fixed O\&M costs of power plant $i(€)$ \\
\hline$C_{i}^{\text {stup }}$ & start-up cost of power plant $i(€)$ \\
\hline $\operatorname{Capt}_{i}^{\max }$ & maximum capacity of power plant in technology cluster $i$ (MW) \\
\hline$C F_{i, y, w, t}$ & $\begin{array}{l}\text { capacity factor of renewable energy sources } i \in I^{\text {res }} \text { during hourly sub-period } t \text { of } \\
\text { week } w \text {, of year } y(\%)\end{array}$ \\
\hline$D R_{y}$ & discount rate for year $y(\%)$ \\
\hline$E F O R_{i}$ & Expected forced outage rate of power plant $i(\%)$ \\
\hline $\operatorname{Load}_{y, w, t}$ & system load at hour $j$, week $w$ in year $y(\mathrm{MWh})$ \\
\hline Maxbudget $_{y}$ & maximum budget available for investment in generation expansion for year $y$ (in \\
\hline & $\mathrm{M} €)$ \\
\hline$M_{i}^{u p}$ & minimum up-time for power plant $i \in I^{t h}$ (hours) \\
\hline$M_{i}^{d n}$ & minimum down-time of power plant $i \in I^{t h}$ (hours) \\
\hline$P_{i}^{\min }$ & $\begin{array}{l}\text { minimum stable power output of power plant in technology cluster } i \in I^{t h} \\
(\mathrm{MW} / \mathrm{h})\end{array}$ \\
\hline Penlevel & renewable penetration level requirement (\%) \\
\hline Pwrstart & maximum output of power plant $i \in I^{t h}$ when started (MW) \\
\hline $\operatorname{Resv} v^{\min }$ & minimum planning reserve margin $(\mathrm{MW})$ \\
\hline$R m p_{i}^{D n m a x}$ & maximum downwards ramping capability of power plant $i \in I^{t h}(\mathrm{MW} / \mathrm{h})$ \\
\hline$R m p_{i}^{U p m a x}$ & maximum upwards ramping capability of power plant $i \in I^{t h}(\mathrm{MW} / \mathrm{h})$ \\
\hline$T_{i}^{c o n s t}$ & construction time of power plant $i$ (years) \\
\hline$T_{i}^{l i f e}$ & expected life-time of new power plant $i$ (years) \\
\hline
\end{tabular}


Continuous Variables:

lns $\quad$ load not served at hourly sub-period $t$ of week $w$, during year $y$ (MW)

pwrgen $_{i, y, w, t} \quad$ energy output of power plant $i$ at hourly sub-period $t$ of week $w$, during year $y$ (MWh)

$\operatorname{shtdn} n_{i, y, w, t} \quad$ shut-down decision of unit $i$ during hourly sub-period $t$ of week $w$ in year $y$

Discrete Variables:

avail_unt $_{i, y} \quad$ availability (commissioning) state of power plant $i$ in year $y$

$i n v_{i, y} \quad$ commissioning decision of power plant $i$ in year $y$

unt_cmt $t_{i, y, w, t} \quad$ commitment status of power plant $i$ during hourly sub-period $t$ of week $w$ in year $y$

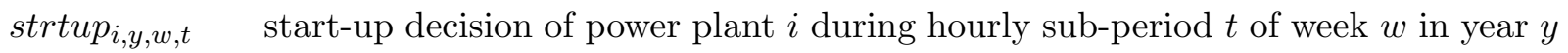

\section{Introduction}

Reliability and security of supply are central considerations for power systems design, and are key to regional and global energy-related policies [1]. Methods for power systems planning have typically ensured key reliability aspects under normal operating conditions and in response to anticipated demand variability and supply disruptions, e.g. due to errors in load forecasts and to unexpected generation units outages. Solutions have been commonly built on capacity adequacy and operating reserves requirements.

Recent objectives of environmental sustainability and the threats coming from severe weather events are challenging in various ways the reliability requirements of power systems design:

- On one hand, low carbon power systems with a high share of intermittent renewable energy sources (IRES) are characterized by a sharp increase in inter-temporal net-load variability. The associated difficulty in anticipating short-term variations brings the need to consider operational flexibility as a critical design concern of future power systems [2]. Power systems operational flexibility under a large share of IRES penetration 
have received attention in recent years. Various studies proposed flexibility metrics [3-6] and planning models [7-11].

- On another hand, increasingly frequent and extreme weather events, such as heat waves, droughts, floods and storms, significantly affect the operational status of power systems. Evidence of power generation disruptions due to such events highlights the fragility of the existing systems. This leads to the need of considering resilience in the planning of future power systems [12], most notably with respect to events such as extreme heat waves, which affect both power load and generation units. Heat waves are among the most worrying weather extremes, due to the expected increase in their frequency and severity in the 21st century [13, 14]. For example, France was particularly impacted by the 2003 summer heat wave, which caused an excess of about 15,000 deaths from 4th to 18th August directly attributable to the heat [15]. By combining peaks of extreme temperature and severe soil and hydrological droughts, this event also affected significantly the energy production sector (mainly via the cooling process of thermal power plants). These last years, numerous regions of the world experienced severe heat waves with comparable effects: Russia in 2010, Texas in 2011, Australia in 2012, India and Southern Pakistan in 2015. Therefore, it is of great importance to design the ability of the energy systems for coping with heat waves in the future.

Recent research has been dedicated to studying the impacts of extreme weather events on power systems. Rocchetta et al. [16] presents a multi-objective optimization of distributed power generation systems considering extreme wind and lightning events. Panteli et al. [17] proposes a probabilistic methodology to assess the resilience degradation of transmission networks subject to extreme wind events. In Cadini et al. [18], an extreme weather stochastic model is applied to a realistic cascading failure simulator of power grids, accounting for the operating conditions that a repair crew may encounter during an extreme weather event. The impacts of water availability on the generation capacity expansion planning is investigated in Cohen et al. [19], and the electricity sector growth is compared under different scenarios 
of water rights. Shao et al. [20] proposes an integrated electricity and natural gas planning model taking into consideration the power grid resilience against storms, earthquakes and floods. Ke et al. [21] studies the potential impacts of heat waves on power grid operation, by quantifying the capacity of thermal power plants as a function of ambient temperature. Whereas most of those studies focus on evaluating the impact of extreme weather threats on the operation of power systems, there exist very few studies that incorporate resilience within the power system design problem itself.

With regards to the above, sustainable and resilient power system design calls for 1) developing integrated flexibility and resilience frameworks for future investment planning on power systems with a high share of IRES penetration and 2) assessing different strategies to mitigate the natural threats and improve system performance. With this perspective, in this work we extend a previously proposed integrated framework for flexible power systems planning [11] to include resilience against extreme weather events. In particular, we consider extreme heat waves and droughts events, and propose systematic methods for assessing their impact on the design and operation of the system. The main contributions of this work are:

- Proposing a set of piece-wise linear models to describe the impact of different scenarios of extreme heat waves and water availability on the derating of thermal power units operation, renewable generation production and system load.

- Explicitly incorporating the extreme weather impact in a modified mixed integer linear programming (MILP) power system planning model to derive adequate system investment decisions.

- Extending our previously proposed quantitative framework for operational flexibility assessment of power systems with a high share of IRES penetration (presented in [11]) to also include their resilience against extreme heat waves and drought events.

- Applying the framework to a practical sized power system planning problem with realistic future climate projections, for demonstrating the relevance of the proposed planning approach in terms of system costs and technology choices. 
The rest of the paper is organized as follows. In Section (2), the piece-wise linear model for describing the impact of extreme heat waves and drought events is described and incorporated into the power system planning problem. A practical size case study generically based on the southern French power system is presented under different climate projections and IRES penetration levels in Section (3). The results shown in Section (4) quantify the impact of the climate change events from the viewpoints of system costs, flexibility and resilience of energy supply. Section (5) presents concluding remarks.

\section{Methodology}

Extreme heat waves affect thermal power plants by reducing their efficiency due to the derating of their cooling capabilities during the event. Load is sensitive to heat waves as it can significantly increase during periods of high temperatures due to increased air conditioning usage. The following section describes a set of piece-wise linear models to quantify these impacts and integrate them within the power system design problem.

\subsection{Piece-wise linear models of the impact of extreme weather events (high temperature and water availability) \\ 2.1.1. Basic model of thermal power plant cooling systems}

Different cooling technologies exist for thermal power generation units. In the event of extreme heat waves, the impact on the different technologies can be different. Since in a power systems planning model the choice among the different cooling systems is a decision variable, it is important to model the specific attributes of each technology separately. In this study, we consider two main cooling technologies:

- Once-through Cooling (OTC) system: the heated cooling water is returned to the water source. A large volume of water from the water source is required.

- Closed-loop cooling (CLC) system: water is circulated in the cooling loop including a cooling tower, where a small portion of cooling water evaporates and is released to atmosphere. Only a small volume of water has to be withdrawn from the water source. 
The required volume of cooling water $V^{r e q}$ for operating a thermal power plant at its maximum capacity $P^{\max }$ is proportional to $P^{\max }$ and inversely proportional to the increase of the temperature in the cooling water $\Delta T[22-24]$, as follows:

$$
\begin{aligned}
& V^{r e q} \propto \frac{P^{\max }(1-\alpha)}{\Delta T} \\
& \Delta T=\max \left(\min \left(T^{\text {out_max }}-T^{\text {in_w }}, \Delta T^{\max }\right), 0\right)
\end{aligned}
$$

where $\alpha$ is the share of waste heat released into air [\%]; this share is small for OTC systems $(\alpha \rightarrow 0)$ whereas it is large for CLC systems $(\alpha \rightarrow 1)$; the permissible temperature increase of the cooling water $\Delta T$ is limited by: 1) the regulated maximum permissible temperature increase of the cooling water $\Delta T^{\max }$, and 2) the regulated maximum permissible temperature of the discharged cooling water $T^{\text {out_max }}[22]$.

We can see that when $T^{\text {in_w }} \leq T^{\text {out_max }}-\Delta T^{\max }$, the maximum permissible temperature increase of the cooling water is only limited by $\Delta T^{\max }$, and the required volume of cooling water $V^{r e q}$ is, thus, a constant value $\left(V^{r e q}=V^{*}\right)$ for $\Delta T=\Delta T^{\max }$. However, a high value of $T^{i n \_w}$ generally leads to an increase in $V^{r e q}$ for operating the plant at its maximum capacity. This increase is significant for OTC systems, whereas it is moderate for CLC systems.

For thermal power plants with CLC systems, it is acceptable to assume that such plants are robust to water shortages and are independent from water availability [22, 23]. Also, the dependency to source water temperature can be neglected since any rise in the water temperature can be compensated by increasing the volume of cooling water $V^{r e q}$ [23]. Instead, CLC systems are mainly affected by the temperature of cooling water circulated back to the condenser, $T^{i n \_c}$, which can be assumed to be close to air temperature [23].

\subsubsection{Extreme weather event impact model}

We consider extreme heat waves and drought events during summer time (JJAS, 21 June20 September) that may force thermal power plants to reduce production owing to scarcity and high temperature of the cooling water. The intensity of the extreme weather event (ewe) 
of heat wave and drought is modeled by:

$$
\text { ewe }=\left[T_{i t}, A_{i t}\right], \forall i \in I, t \in T
$$

where $T_{i t}$ is the hourly air temperature at plant $i$, from which we can calculate the related stream temperature $T_{i}^{i n \_w}$ based on air-water interaction as follows [24]:

$$
T_{i t}^{i n \_w}=t^{\min }+\frac{t^{\max }-t^{\min }}{1+e^{\gamma\left(t^{i p}-T_{i t}\right)}}
$$

The parameters for the air/water temperature relationship are derived from the literature $[22,25,26]$ : the minimum stream temperature is assessed to be $t^{\min }=0^{\circ} \mathrm{C}$, the maximum stream temperature to be $t^{\max }=30.4^{\circ} \mathrm{C}$, the steepest slope to be $\gamma=0.14$ and the air temperature at the inflection point to be $t^{i p}=16.5^{\circ} \mathrm{C}[27]$. The parameter of the extreme weather event $A_{i t}$ represents the hourly availability (percentage) of intake cooling flow at plant $i$, time $t$ and is defined by:

$$
A_{i t}=\frac{\min \left(V_{i t}^{s r c}, V_{i}^{c p t y}\right)}{V_{i}^{*}}
$$

where $V_{i t}^{\text {src }}$ is the permissible amount of water flow that can be taken from the water source at plant $i$ at time $t, V_{i}^{c p t y}$ represents the water extraction capacity of the plant and $V_{i}^{*}$ is the constant amount of the required volume of intake cooling water for plant $i$ when the intake

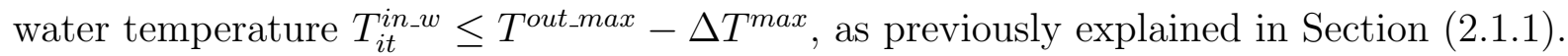

For thermal power plants using the OTC system, $\forall i \in I^{\text {th_otc }}$, the ratio of $P_{i t}^{\text {usable }}$ to $P_{i}^{\max }$ as a function of $T_{i t}$ and $A_{i t}$ can be expressed by the following piece-wise linear equations for different ranges of $T_{i t}$ :

$$
z_{i t}^{\text {ewe }}= \begin{cases}P_{i t}^{\text {usable }} / P_{i}^{\max }=\min \left(1, A_{i t}\right), & T_{i t}^{i n_{1} \_w} \leq T_{\text {health }} \\ \min \left(1, A_{i}\right) \cdot\left[1-\beta \cdot\left(T^{i n \_w}-T_{\text {health }}\right)\right], & T_{\text {health }} \leq T_{i t}^{i n \_w} \leq T_{\text {risk }} \\ \min \left(1, A_{i t}\right) \cdot \delta \cdot \frac{\left(T^{\text {out_max }}-T_{i t}^{i n \_w}\right)}{\Delta T^{\text {max }}}, & T_{\text {risk }} \leq T_{i t}^{\text {in_w }} \leq T_{\text {shutdown }} \\ 0, & T_{i t}^{i n \_w} \geq T_{\text {shutdown }}\end{cases}
$$

where $\beta$ is the efficiency degrading rate when $T^{i n \_w}$ is in the range of $\left[T_{\text {health }}, T_{\text {risk }}\right]$ and $T_{\text {risk }}$ is defined to represent the temperature when the actual maximum discharge of waste of heat 
is equal to the designed value and is given by:

$$
T_{\text {risk }}=T^{\text {out_max }}-\Delta T^{\max } \cdot \frac{1}{A_{i t}}
$$

Coefficient $\delta$ can be calculated based on the continuation of the piece-wise linear functions (6) at $T_{i t}^{i n \_w}=T_{\text {risk }}$ and is given by:

$$
\delta=A_{i t}+\beta \cdot \Delta T^{\max }-\beta \cdot A_{i t} \cdot\left(T^{\text {out_max }}-T_{\text {health }}\right)
$$

The above piece-wise linear equations (6) hold when $T_{\text {risk }} \geq T_{\text {health }}$, i.e., $A_{i} \geq \Delta T^{\text {max }} /\left(T^{\text {out_max }}\right.$ $\left.T_{\text {health }}\right)$. For the case where $T_{\text {risk }} \leq T_{\text {health }}$, i.e., $A_{i} \leq \Delta T^{\text {max }} /\left(T^{\text {out_max }}-T_{\text {health }}\right) \triangleq A_{i t}^{\text {shtg }}$, we can simplify the piece-wise linear functions (6) as follows:

$$
z_{i t}^{\text {ewe }}= \begin{cases}\min \left(1, A_{i t}\right), & T_{i t}^{\text {in_w }} \leq T_{\text {health }} \\ \min \left(1, A_{i t}\right) \cdot A_{i t}^{\text {shtg }} \cdot \frac{\left(T^{\text {out_max }}-T_{i t}^{\text {in_w }}\right)}{\Delta T^{\text {max }}}, & T_{\text {health }} \leq T_{i t}^{\text {in_w }} \leq T_{\text {shutdown }} \\ 0, & T_{i t}^{\text {in_w }} \geq T_{\text {shutdown }}\end{cases}
$$

For a thermal plant using the CLC system, $\forall i \in I^{t h}$ clc , the following piece-wise linear functions are used to describe the impact of the air temperature $\left(T_{i t} \approx T_{i t}^{i n_{c} c}\right)$ on the usable power capacity:

$$
z_{i t}^{\text {ewe }}= \begin{cases}1, & T_{i t} \leq T_{\text {health_air }} \\ 1-\rho \cdot\left(T_{i t}-T_{\text {health_air }}\right), & T_{i t} \geq T_{\text {health_air }}\end{cases}
$$

For renewable generation units, wind power and solar photovoltaic (PV) systems do not require water to generate electricity and, thus, the capacity of renewable generation will not be affected largely by an extreme heat wave and drought event. To obtain the future PV and wind power potential capacity factor (CF), we use the recent CMIP5 data of high-resolution climate projections (fully described in section (3.2)), together with the wind and PV power production models proposed in the literature.

Since the wind speed at the turbine height is not a standard output of the climate projection model, we use near-surface wind speeds at 10 meters $V_{10 m}$ and assume a powerlaw relationship for extrapolating the vertical wind profile $[28,29]$. The velocity at hub 
height $H$ is calculated as:

$$
V_{H}=V_{10 m} \cdot\left(\frac{H}{10}\right)^{\frac{1}{7}}
$$

Then, the wind speed $V_{H}$ is converted into turbine-generated electric power capacity factor $z_{i t}, \forall i \in I^{\text {res-wind }}, t \in T$ using a standard power curve, described as follows:

$$
\forall i \in I^{\text {res-wind }} z_{i}= \begin{cases}0, & \text { if } V_{H}<V_{l} \text { or } V_{H}>V_{0} \\ \frac{V_{H}^{3}-V_{l}^{3}}{V_{R}^{3}-V_{l}^{3}}, & \text { if } V_{l} \leq V_{H}<V_{R} \\ 1, & \text { if } V_{R} \leq V_{H}<V_{0}\end{cases}
$$

where $V_{l}, V_{R}$ and $V_{0}$ are the cut-in, rated and cut-out velocity of a wind turbine, respectively. Wind power capacity factor is calculated at the grid cell level (defined in the climate projection model) assuming a unique turbine model for all grid cells $\left(H=80 \mathrm{~m}, V_{l}=3.5 \mathrm{~m} / \mathrm{s}, V_{R}=\right.$ $\left.12 \mathrm{~m} / \mathrm{s}, V_{0}=25 \mathrm{~m} / \mathrm{s}\right)$, as in $[30,31]$

PV power generation potential depends on solar irradiance, named surface-downwelling shortwave (i.e., wavelength interval $0.2-4.0 \mu \mathrm{m})$ radiation $\left(R_{s d s}\right)$ in the climate models, and other atmospheric variables affecting panel efficiency, i.e., surface air temperature (Tas) and surface wind velocity $\left(V_{10 m}\right)$. The PV power generation can be expressed as $[32,33]$ :

$$
\forall i \in I^{r e s-p v}, z_{i}=\left[1+\gamma\left(T_{\text {cell }}-T^{0}\right)\right] \cdot \frac{R_{s d s}}{R_{s d s}^{0}}
$$

where the upper script 0 refers to standard test conditions for which the nominal capacity of a PV device is determined as its measured power output $\left(R_{s d s}^{0}=1000 \mathrm{Wm}^{-2}, T^{0}=\right.$ $25^{\circ} \mathrm{C}$ ). Parameter $\gamma$ is set at $-0.005^{\circ} \mathrm{C}^{-1}$, considering the typical temperature efficiency of monocrystalline silicon solar panels [32]. Finally, the PV cell temperature $T_{\text {cell }}$ is obtained as:

$$
T_{\text {cell }}=c_{1}+c_{2} T_{a s}+c_{3} R_{s d s}+c_{4} V_{10 m}
$$

where $c_{1}=4.3^{\circ} \mathrm{C}, c_{2}=0.943, c_{3}=0.028^{\circ} \mathrm{Cm}^{2} \mathrm{~W}^{-1}$ and $c_{4}=-1.528^{\circ} \mathrm{Csm}^{-1}[32,34]$.

After obtaining the grid cell level renewable (wind and PV) power capacity factors, then, the regional renewable power potentials can be obtained by averaging all the grid cell levels inside a given region. 
Power demand is usually sensitive to climatic conditions. To capture this, the power demand in the extreme weather event is represented by:

$$
L_{t}^{e w e}=l_{t}+C^{l} \cdot\left(\bar{T}_{t}-\bar{T}_{t}^{r e f}\right)
$$

where $C^{l}$ is the temperature sensitivity coefficient of power load, e.g., it is around $+500 M W /+1^{\circ} \mathrm{C}$ during the summer time in France [35]. Here $\bar{T}_{t}$ and $\bar{T}_{t}^{r e f}$ represent the geographical average values of the projected air temperature and historical reference air temperature, respectively.

\subsection{Power system planning model with short-term operational constraints}

Operational flexibility in long term planning should be accounted for by considering the short-term technical constraints of the generating units, such as the unit commitment of generation units, their ramping capabilities and minimum up and down times, to name a few [11]. We refer to this class of planning models as the integrated generation expansion planning (IGEP) models, since it combines both long-term investment constraints and short-term unit commitment constraints within a single optimization. The multi-period IGEP planning model used here seeks to minimize the total discounted system cost over the whole time horizon. These costs include: annualized equivalent investment costs, fixed operation and maintenance costs, and variable operation costs of the power system (fuel cost, start-up costs and cost of load not served). The plans obtained are subject to long-term constraints including the budget limit, adequacy requirement, renewable penetration level, and short-term constraints including supply-demand balance, generation limits, unit commitment decisions, ramping limits and minimum up and down times. The model is formulated as a mixed integer linear program (MILP) considering annual long-term generation expansion planning constraints and hourly short-term unit commitment decisions.

\subsubsection{Objective function}

The objective is the minimization of the total discounted costs over the planning horizon. Equation (16) represents the total investment costs in new units, equation (17) represents the total production costs including start-up costs and cost of LNS, and equation (18) represents the fixed operation and maintenance (O\&M) costs. It should be noted that the investment 
cost considered in this model is the Equivalent Annual Cost (EAC) that is obtained by using the AnnuityFactor ${ }_{i}$ calculated as: AnnuityFactor ${ }_{i}=\frac{1-(1+D R)^{- \text {Tlife }_{i}}}{D R}$. This ensures the proper relationship between the annual investment and operational costs and the correct evaluation of the different investment options having different life spans Tlife $e_{i}$

$$
\begin{aligned}
& \min _{\text {cost }} \sum_{y \in Y}(1+D R)^{-y} \cdot \text { AnnuityFactor } \\
& \cdot \\
& +\sum_{i \in I^{\text {new }}} C_{i}^{\text {inv }} \cdot \text { Capt }_{i}^{\text {max }} \cdot \text { inv }_{i, y} \\
& +\sum_{y \in Y}(1+D R)^{-y} \cdot \sum_{w \in W} \text { Weight } \cdot \sum_{t \in T}\left[\sum_{i \in I}\left(C_{i, y}^{\text {marg }} \cdot \text { pwrgen }_{i, y, w, t}\right)\right. \\
& \left.+\sum_{i \in I^{\text {th }}}\left(C_{i}^{\text {stup }} \cdot \operatorname{stup}_{i, y, w, t}\right)+C^{\text {lns }} \cdot \operatorname{lns}_{y, w, t}\right] \\
& +\sum_{y \in Y}(1+D R)^{-y} \cdot \sum_{i \in I} C_{i, y}^{O M} \cdot \text { Capt }_{i}^{\text {max }} \cdot \sum_{l=1}^{y} \text { inv }_{i, l}
\end{aligned}
$$

\subsubsection{Constraints}

Since we consider a multi-period planning horizon, Eq. (19) keeps track of the investment decisions made in year $y$ taking into account the construction time of the unit following:

$$
\text { avail_unt }_{i, y}=\sum_{l=1}^{y} i n v_{i, l-T_{i}^{\text {const }}+1}, \quad \forall i \in I^{\text {new }}, y \in Y \backslash\left[T_{i}^{\text {const }}-1\right]
$$

The maximum allowable discounted investment budget is limited in Eq (20) such as:

$$
(1+D R)^{-y} \cdot \sum_{i \in I^{\text {new }}} C_{i}^{i n v} \cdot \text { Capt }_{i}^{\max } \cdot \text { inv }_{i, y} \leq \text { Maxbudget }_{y}, \quad \forall y \in Y
$$

Eq (21) ensures that the adequacy level requirement is met by ensuring enough firm capacity to satisfy a reserve margin above the maximum predicted load:

$$
\sum_{i \in I^{t h}}\left(\text { Capt }_{i}^{\text {max }} \cdot \text { avail_unt }_{i, y}\right) \geq\left(1+\operatorname{Resrv}^{\min }\right) \cdot \max _{w, t}\left(\operatorname{Load}_{y, w, t}\right), \quad \forall y \in Y
$$

The renewable penetration level required in the system is set through Eq (22):

$$
\sum_{i \in I^{\text {res }}} \text { avail_unt }_{i, y} \cdot \text { Capt }_{i}^{\max } \geq \text { Penlevel } \cdot \sum_{i \in I} \text { avail_unt }_{i, y} \cdot \text { Capt }_{i}^{\max }, \quad \forall y \in Y
$$


Eq (23) ensures the coupling between investment and operational decisions:

$$
\text { unt_cmt }_{i, y, w, t} \leq \text { avail_unt }_{i, y} \quad \forall i \in I^{\text {thermal }}, t \in T, w \in W, y \in Y
$$

The hourly supply and demand balance as well as the amount of LNS is constrained by Eq (24):

$$
\sum_{i \in I} \operatorname{pwrgen}_{i, y, w, t}+\operatorname{lns}_{y, w, t}=\operatorname{Load}_{y, w, t} \quad \forall t \in T, w \in W, y \in Y
$$

Eq (25) constraints the hourly unit commitment decisions by the startup and shutdown decisions:

$$
\begin{gathered}
u n t_{-} c m t_{i, y, w, t}-u n t_{-} c m t_{i, y, w, t-1}=s t u p_{i, y, w, t}-s h t d n_{i, y, w, t}, \\
\forall i \in I^{t h}, t \in T /\{1\}, \\
w \in W, y \in Y
\end{gathered}
$$

The hourly maximum and minimum production levels for thermal units are given in Eq (26) and $\mathrm{Eq}(27)$, respectively:

$$
\begin{gathered}
\text { pwrgen }_{i, y, w, t} \leq\left(1-E F O R_{i}\right) \cdot \text { Capt }_{i}^{\text {max }} \cdot \text { unt_cmt }_{i, y, w, t}, \quad \forall i \in I^{t h}, t \in T, w \in W, y \in Y \\
\text { pwrgen }_{i, y, w, t} \geq P^{m i n} \cdot \text { unt_cmt }_{i, y, w, t} \quad \forall i \in I^{t h}, t \in T, w \in W, y \in Y
\end{gathered}
$$

The renewable sources production is limited by the hourly capacity factor $C F$ as given in $\mathrm{Eq}(28)$ :

$$
\text { pwrgen }_{i, y, w, t} \leq \text { avail_unt }_{i, y} \cdot \text { Capt }_{i}^{\text {max }} \cdot C F_{i, y, w, t}, \quad \forall i \in I^{r e s}, t \in T, w \in W, y \in Y
$$

Eq (29) and Eq (30) constraint the hourly upwards and downwards ramping capabilities for thermal units, respectively:

$$
\begin{gathered}
\text { pwrgen }_{i, y, w, t}-\text { pwrgen }_{i, y, w, t-1} \leq \text { unt_cmt } \\
\forall i, y, w, t-1 \\
\forall i \in I^{t h}, t \in T \backslash\{1\}, w \in W, y \in Y \\
\text { pwrgen }_{i, y, w, t-1}-\text { pwrgen }_{i, y, w, t} \leq \\
\text { unt_cmt }_{i, y, w, t-1} \cdot \operatorname{Rmp}_{i}^{\text {Dnmax }} \\
\forall i \in I^{t h}, t \in T \backslash\{1\}, w \in W, y \in Y
\end{gathered}
$$


Finally, Eq (31) and Eq (32) ensures that the minimum allowable up and down times for thermal units are respected:

$$
\begin{gathered}
\text { unt_cmt }_{i, y, w, t} \geq \sum_{\tau=t-M_{i}^{u p}}^{t} \operatorname{strtup}_{i, y, w, \tau} \forall i \in I^{t h}, t \in T \backslash\left[M_{i}^{u p}\right], w \in W, y \in Y \\
\text { avail_unt }_{i, y}-\text { unt_cmt }_{i, y, w, t} \geq \sum_{\tau=t-M_{i}^{d n}}^{t} \operatorname{shtdn_{i,y,w,\tau },} \quad \forall i \in I^{t h}, t \in T \backslash\left[M_{i}^{d n}\right], \\
w \in W, y \in Y
\end{gathered}
$$

\subsubsection{Integrating resilience requirement into system design}

The impact of an extreme weather event to the power generation system is measured by the decrease of the generation capacity of affected thermal and PV plants, and the increase of power demand, as given above. Then, the power generation system resilience is evaluated by a deterministic metric, which is referred to as the total load not served (LNS) during the period of the extreme weather event, and is defined as:

$$
\begin{aligned}
& L S_{y t}^{\text {ewe }}=\left(\operatorname{Load}_{y t}^{\text {ewe }}-\sum_{i \in I} \text { pwrgen }_{\text {iyt }}^{\text {ewe }}\right), \quad \forall y \in Y, t \in T^{\text {ewe }} \\
& \text { pwrgen }_{\text {iyt }}^{\text {ewe }} \leq z_{\text {iyt }}^{\text {ewe }} \cdot \operatorname{Capt}_{i}^{\text {max }} \cdot \text { unt_cmt }_{\text {iyt }}, \quad \forall i \in I, y \in Y, t \in T^{e w e} \\
& \sum_{t \in T^{\text {ewe }}} L S_{y t}^{\text {ewe }} \leq L S^{\text {max }}, \quad \forall y \in Y
\end{aligned}
$$

where $u n t_{-} c m t_{i y t}$ is the unit commitment state of generation units of technology $i$ at time $t$ in year $y$, and $z_{i y t}^{\text {ewe }}$ is the efficiency factor of the generation units of technology $i$ during the extreme weather event, calculated using the above piece-wise linear equations (6)-(14), and $T^{\text {ewe }}$ is the total duration of the event. Equation (33) calculates the total amount of load shedding $L S$ in each year $y$ during the extreme weather event as the difference between the hourly demand and the total power generation from all power units. Equation (34) limits the power generation output pwrgen of generation units of technology $i$ at year $y$ during the extreme weather event $t \in T^{e w e}$ to the efficiency factor $z_{\text {iyt }}^{\text {ewe }}$. Finally, constraint (35) limits 
the amount of load shedding allowed during the extreme weather event $L S_{y t}^{e w e}$ to a maximum limit $L S^{\max }$.

It should be noted that the resilience metric used here is focused on the ability of the power system to mitigate the impact of the extreme heat wave and drought events and not on the recovery from those events. This is because in these specific extreme weather events the main action is to reduce the thermal units production levels or to shut them down completely to avoid overheating and further damages to the units, so that recovery of normal operation is immediate once weather conditions go back to normal.

\subsubsection{Assessing the flexibility of the power system design}

High shares of IRES production increase the inter-temporal variability of the remaining net system load. Enough available thermal units, then, need to be operational and sufficiently flexible to cope with these variations and ensure production reliability. Proper metrics are needed to evaluate the operational flexibility of the plans obtained under different weather and IRES scenarios.

In this work, we adopt the Expected Flexibility Shortfall (EFS) metric presented in [11]. This probabilistic metric takes into account detailed technical and temporal attributes of the thermal units to quantify the system ability to meet inter-temporal variations. Figure (1) shows a schematic illustration of the EFS calculation method. 


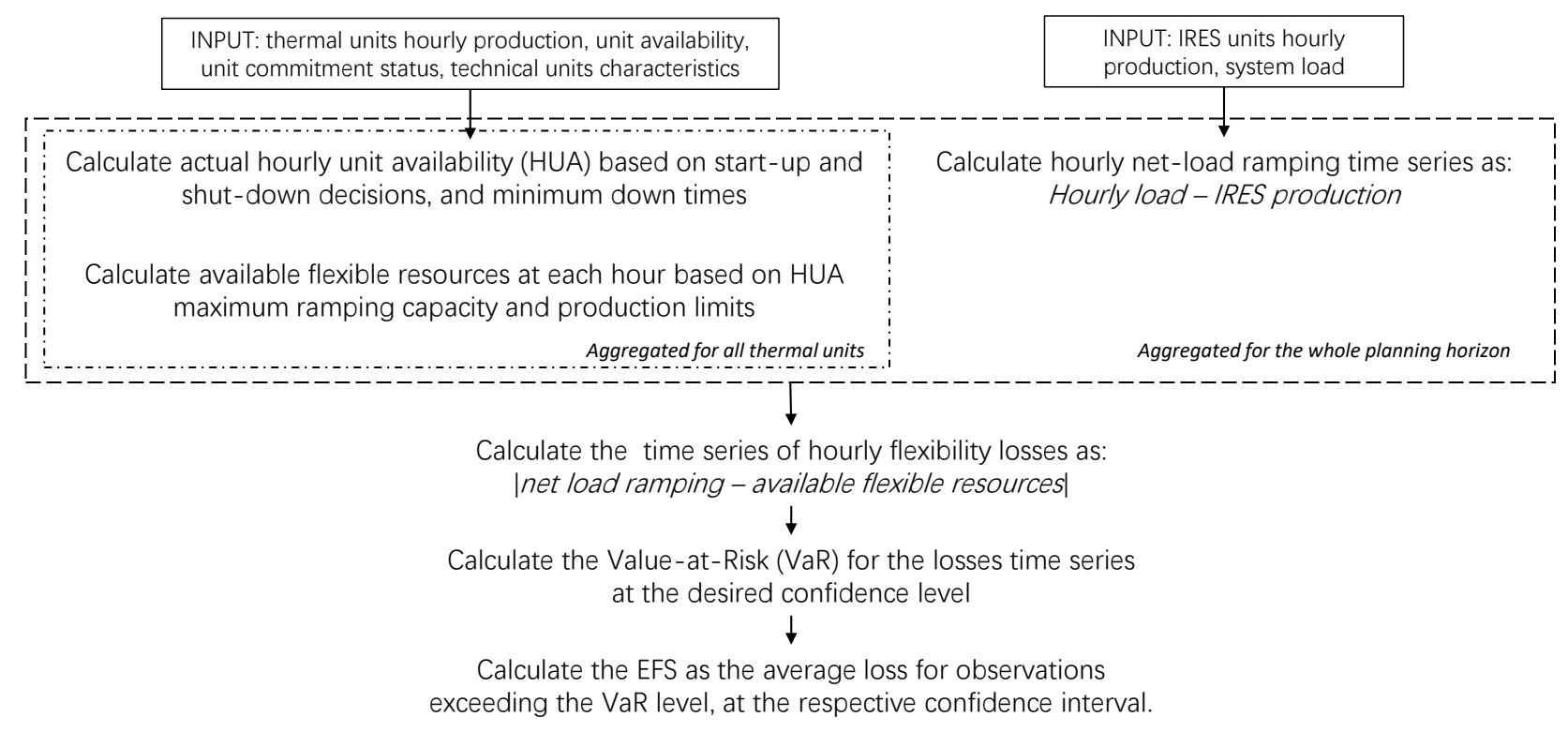

Figure 1: EFS calculation

\section{Power system characteristics and climate scenarios}

\subsection{Power system modeling}

We consider a multi-annual planning horizon representing the period between the year 2041 to 2046. Linear regression is used to obtain the system hourly load from the historical electricity load time series of France from the year 2008 to 2012 (publicly available at [36]), assuming a growth of $1 \%$ to $1.5 \%$ from the beginning to the end of the planning horizon. The cost data for the generation technologies considered for the expansion planning are based on the IEA/NEA Projected Costs of Generating Electricity report (2015) [37]; the remaining technical characteristics are assumed based on values found in the literature and are summarized in Table (1). 
Table 1: Technical parameters for power generation technologies

\begin{tabular}{|c|c|c|c|c|c|}
\hline Technology & Nuclear & Coal & CCGT & Solar-PV & On-shore Wind \\
\hline Maximum Capacity per installed unit $[M W]$ & 1400 & 1100 & 550 & 60 & 80 \\
\hline Minimum stable load $[M W]$ & 700 & 550 & 165 & 0 & 0 \\
\hline Maximum upward ramping $[M W h / \min ]$ & $0.5 \% P_{n} / \mathrm{min}$ & $1.5 \% P_{n} / \min$ & $5 \% P_{n} / \mathrm{min}$ & / & / \\
\hline Maximum downward ramping $[M W h / \mathrm{min}]$ & $0.5 \% P_{n} / \mathrm{min}$ & $1.5 \% P_{n} / \mathrm{min}$ & $5 \% P_{n} / \mathrm{min}$ & / & / \\
\hline Minimum up time [hours] & 12 & 6 & 3 & / & / \\
\hline Minimum down time [hours] & 24 & 10 & 5 & / & / \\
\hline Start-up cost $[k €]$ & 15.0 & 11.26 & 7.53 & / & / \\
\hline
\end{tabular}

Thermal generation units can be equipped with one of two different cooling technologies, that have different cost and technical characteristics. Under normal conditions, cooling towers with recirculating water (CLC) reduce the overall efficiency of power plants by $2-5 \%$ compared to once-through use of water from seas, lakes or large streams (OTC). Thus, these towers are associated with larger operational/marginal costs compared to OTC systems. Moreover, the investment costs of CLC systems are around 20\% higher than those for OTC systems. Table (2) summarizes the specific technical and cost parameters of the generation units equipped with each cooling technology [23, 38, 39].

Table 2: Technical and economic characteristics for the different generation technologies

\begin{tabular}{lccccccc}
\hline $\begin{array}{l}\text { Technology } \\
{[i]}\end{array}$ & $\begin{array}{c}\beta / \rho / C^{p v} \\
{[\%]}\end{array}$ & $\begin{array}{c}T_{\text {health }} / T_{\text {health_air }} / T^{\text {ref_pv }} \\
{\left[{ }^{\circ} \mathrm{C}\right]}\end{array}$ & $\begin{array}{c}T_{\text {shutdown }} \\
{\left[{ }^{\circ} \mathrm{C}\right]}\end{array}$ & $\begin{array}{c}T^{\text {out_max }} \\
{\left[{ }^{\circ} \mathrm{C}\right]}\end{array}$ & $\begin{array}{c}\Delta T^{\text {max }} \\
{\left[{ }^{\circ} \mathrm{C}\right]}\end{array}$ & $\begin{array}{c}C_{i}^{\text {inv }} \\
{[\mathrm{M} € / M W]}\end{array}$ & $\begin{array}{c}C_{i}^{\text {mrgl }} \\
{[€ / M W h]}\end{array}$ \\
\hline Nuclear-OTC & 0.44 & 15 & 32 & 32 & 10 & 3.95 & 13.84 \\
Nuclear-CLC & 0.44 & 10 & $/$ & $/$ & $/$ & 4.74 & 14.11 \\
Coal-OTC & 0.97 & 15 & 32 & 32 & 10 & 2.08 & 38.97 \\
Coal-CLC & 0.94 & 10 & $/$ & $/$ & $/$ & 2.60 & 39.75 \\
CCGT-OTC & 0.31 & 15 & 32 & 32 & 10 & 1.02 & 70.16 \\
CCGT-CLC & 0.30 & 10 & $/$ & $/$ & $/$ & 1.22 & 71.50 \\
Solar-PV & 0.50 & 25 & $/$ & $/$ & $/$ & 1.5 & 1.71 \\
On-Shore Wind & $/$ & $/$ & $/$ & $/$ & 1.9 & 2.16 \\
\hline
\end{tabular}

Within the optimization planning framework, the investment decisions are grouped by technology option using the unit clustering method proposed in [40]. The yearly load is optimally approximated by four representative weeks as proposed in [41] and the chronological order within each week is maintained. This is especially important for correctly capturing the operational flexibility attributes of the system while ensuring the computational tractability of the optimization problem. An additional week corresponding to the one containing the 
peak summer load is, then, added to simulate the impact of the heat wave and drought events during summer time.

\subsection{Climate projections data of heat wave and drought events}

Historical baseline temperature as well as future temperature projections for the years 2041 to 2046 are based on data obtained from the Coupled Model Intercomparison Project (CMIP5) experiments [42]. Similarly, wind speeds and solar irradiance data used to calculate the wind and solar CF are obtained from the CMIP5 experiments, following the models presented in section (2.1.2). We consider three Representative Concentration Pathways (RCPs) that cover the impact of different trajectories of greenhouse gas concentration on future climate, compared to pre-industrial levels. In particular, we consider the RCP 8.5, RCP 4.5 and RCP 2.6, which represent an increased in radiative forcing of $+8.5 \mathrm{Wm}^{-2}$, $+4.5 \mathrm{Wm}^{-2}$ and $+2.6 \mathrm{Wm}^{-2}$ respectively, compared to pre-industrial values. Table (3) summarizes the details of the CMIP5 experiments used for the different climate projections.

Table 3: Details of the experiments used for the historical and projected temperature scenarios

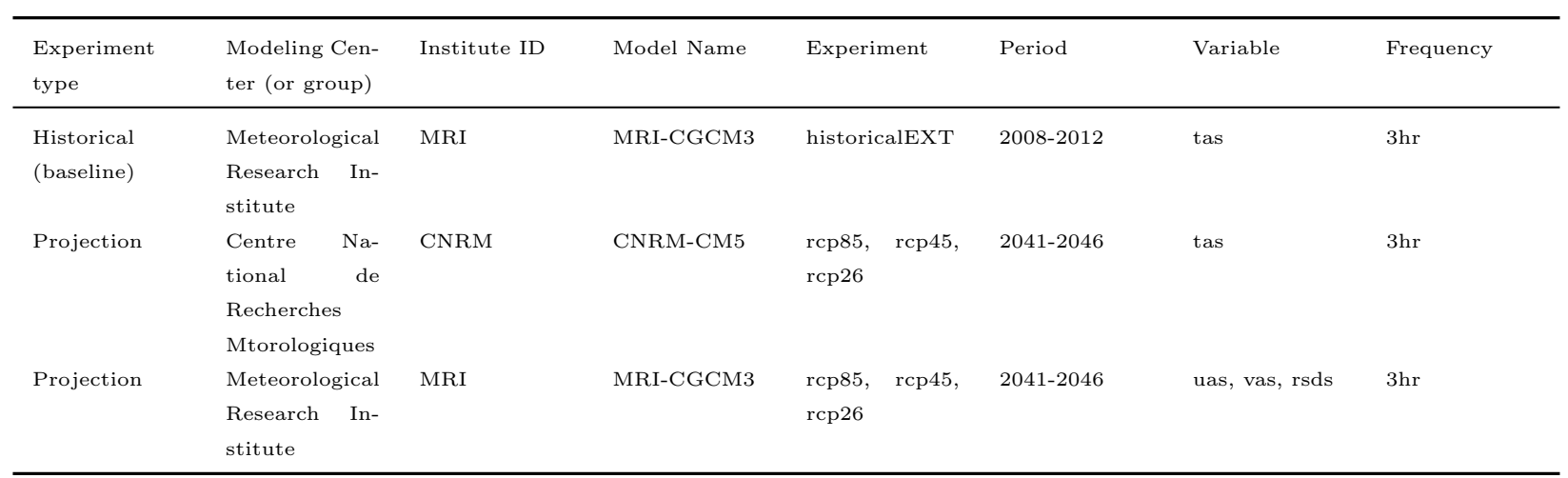

Since we are primarily interested in extreme weather scenarios related to the region of southern France, the climate data considered have been limited to the geographical scope of interest: that is, data spanning the longitudinal and latitudinal scope of approximately $\left(W 2^{\circ} 35^{\prime} 00^{\prime \prime}-E 8^{\circ} 10^{\prime} 00^{\prime \prime}\right)$ and $\left(N 46^{\circ} 06^{\prime} 00^{\prime \prime}-N 41^{\circ} 19^{\prime} 00^{\prime \prime}\right)$, respectively. To quantify the impact of an extreme heat wave, the average temperature time series as well as the average wind and solar CF are, then, computed for the geographical area considered, for each pro- 
jected climate scenarios. Regarding water availability levels, different water level scenarios during the heat wave events are assumed to cover: high availability levels $(\mathrm{A}>1)$, normal levels $(\mathrm{A}=1)$ and low availability levels $(\mathrm{A}<1)$.

\section{Results and discussion}

\subsection{Impact of extreme heat wave and drought events on system load and efficiency of power} generation

We start our investigation with a focus on future climate parameters obtained from the RCP 8.5 experiments, which is the representative concentration pathway assuming no decrease in current carbon emission trends throughout the 21st century. Significant temperature increase during the summer period is observed under the Representative Concentration Pathway (RCP 8.5), compared to the historical baseline scenario. The impact of this temperature increase on the load and power generation units are computed for a typical summer week for each year of the planning horizon. As an example, Figure (2) illustrates the projected temperature increase and its impact on system load during the period between the 30th of July and the 6th of August for the year 2041 in southern France, compared to the historical average levels in the same period and location. The temperature difference is seen to reach levels of $+9.2^{\circ} \mathrm{C}$, while its impact on the system load (calculated as per the proposed impact model) can increase up to +1840 MWh. Similar order of differences are observed for the other planning years considered.

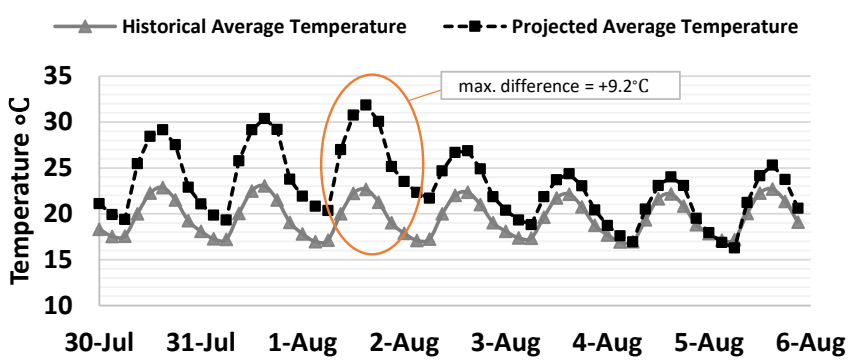

(a) Temperature difference

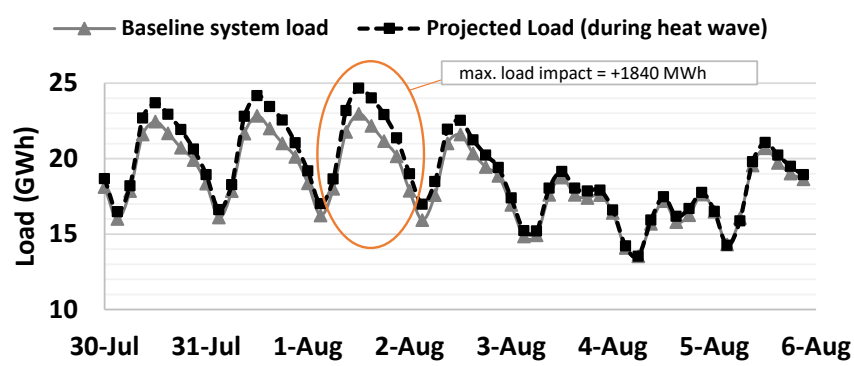

(b) Load difference

Figure 2: Temperature difference and its impact on system load during the period between the 5th and the 12th of August, for both the baseline and the projected scenarios 
The effect of heat wave and water shortages on the efficiency of thermal units depends on the cooling technology deployed. We consider three different levels of water availability and calculate their impact on the efficiency of thermal units during the heat wave event. Figure (3) illustrates the resulting efficiency for nuclear power plants during a heat wave and under different water availability levels, using data for the year 2041. It can be seen that OTC-based generators are highly affected by water shortages, compared with CLC units, which are impacted by the heat wave but maintain the same efficiency levels regardless of the water availability level.

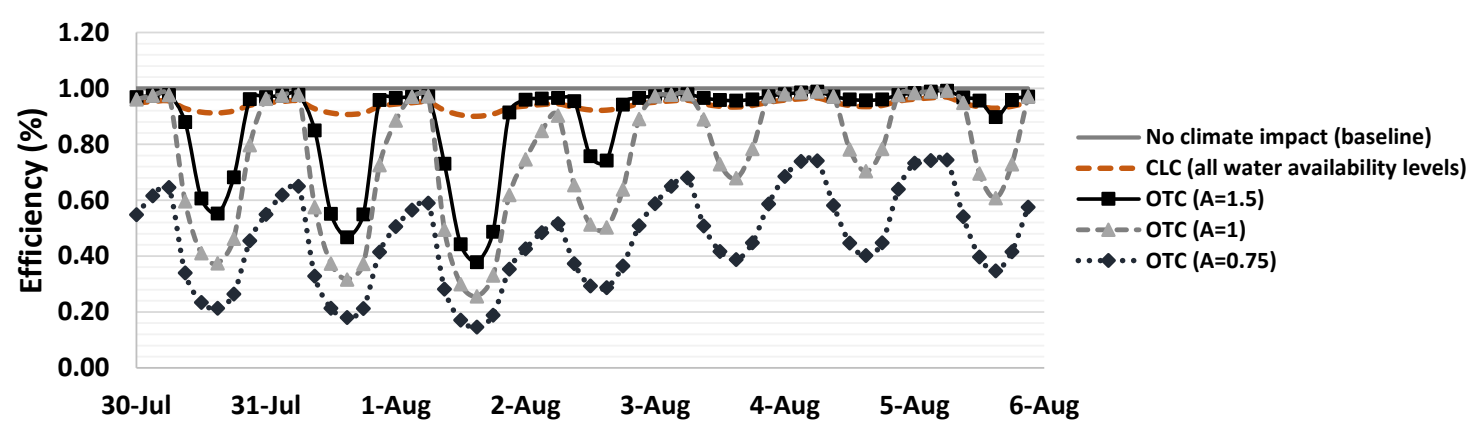

Figure 3: Example of nuclear generation units efficiency derating during a heat wave event for different cooling technologies (OTC and CLC) and under different water availability scenarios (high availability: A $>1$, normal availability: $\mathrm{A}=1$, low availability $\mathrm{A}<1$ )

\subsection{Resilient power system planning vs conventional planning}

Resilient power systems planning should account for the impact of extreme weather events as an integral part of the planning problem, as discussed in the previous sections. We compare the resilient plans (denoted RP) to conventional plans (CP), obtained assuming no climate impact on the efficiency of the generation units. CP future investment plans are, then, used to simulate operation under different realizations of climate scenarios, to assess operational performance. We focus first on the results obtained under no IRES penetration level requirements.

The total amount of load not served (LNS) during the heat wave period is taken as the primary performance measure for the plans obtained. Figure (4) illustrates the resulting LNS for both RP and CP under the extreme weather events. The results show a significant 
load loss for the conventionally planned systems, that sharply increases with the worsening of the climate conditions. The loss reaches up to $851 \mathrm{GWh}$ under the worst scenario of climate impact. This is not the case for the RP, which are shown to suffer an LNS significantly lower than $\mathrm{CP}$, with a maximum of $17 \mathrm{GWh}$ under the worst scenario of climate impact.

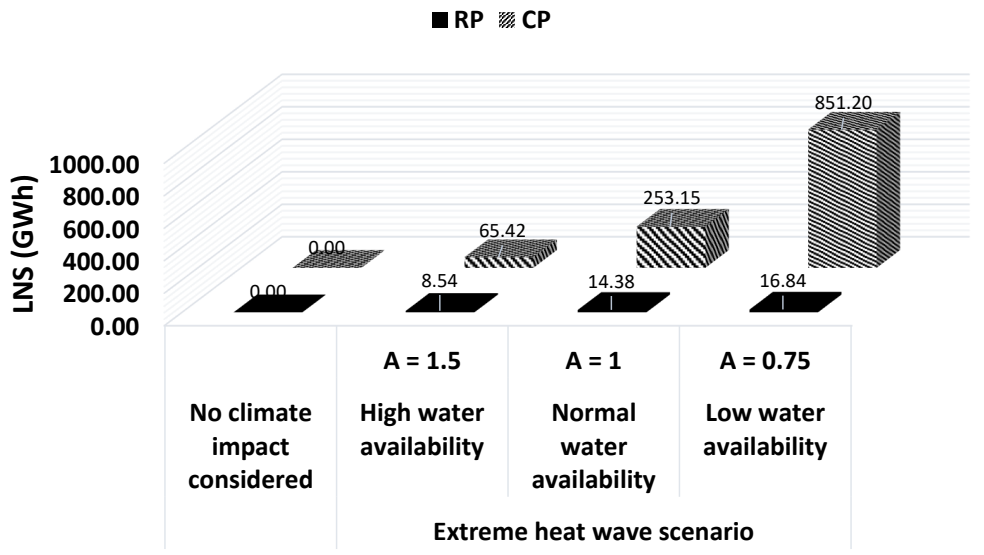

Figure 4: LNS during different extreme weather events. Comparison between RP and CP under no IRES penetration.

In terms of system costs, RP have overall higher annualized investment and operational costs compared to CP, as can be seen in Figure (5). This is directly related to the fact that for RP the extreme weather impact on the power system is taken into account and so the plan compensates the lower thermal units efficiency by investing in more and better performing units. The slightly higher investment and operational costs, however, are fully offset by the reductions in LNS costs, as can be seen in Figure (5). The maximum difference between the total annualized investment and operation costs of the RP compared to the CP is equal to $1.23 \mathrm{~B} €$ (low water availability scenario in Figure (5)), while the LNS cost saving for the same scenario is around $9.52 \mathrm{~B} €$. 


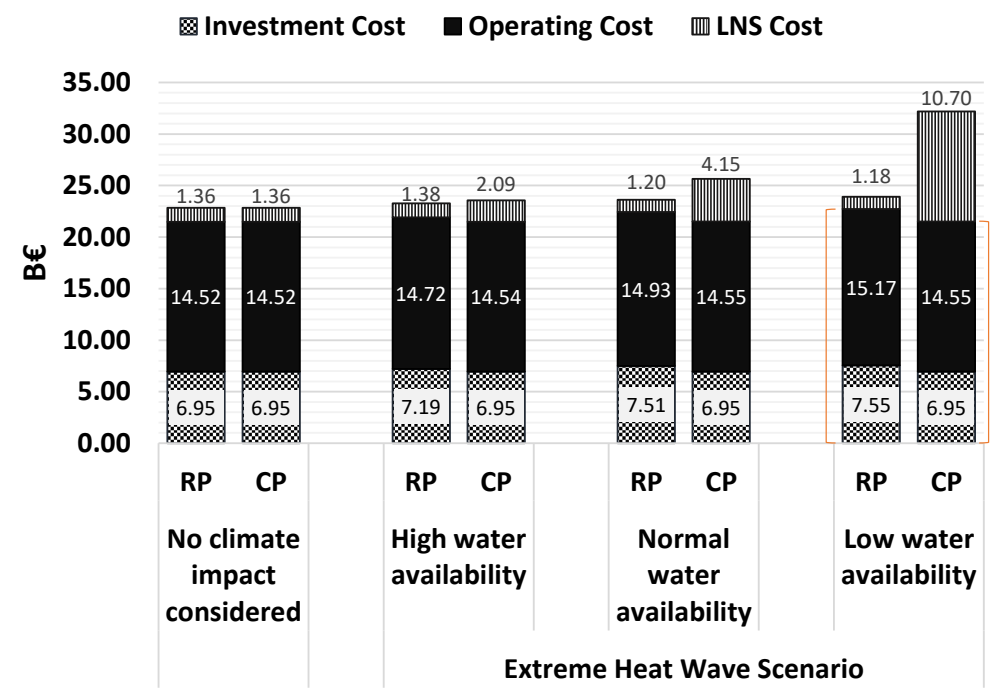

Figure 5: Comparison between RP and CP costs subject to different extreme weather events under no IRES penetration.

Next, we extend the analysis to evaluate the impact of increasing IRES penetration levels on the system performance. Most notably we consider 0\%, 25\% and 50\% IRES energy penetration levels (percentages of total system load) and solve the optimization problems under all extreme weather events, for both the RP and CP.

Figure (6) shows the impact of the increasing share of IRES levels on the LNS of the system during the extreme weather events, for RP and CP. Higher IRES penetration has a clear effect on reducing the amount of LNS during the extreme events. RP maintain low LNS levels in all cases considered, and slightly improves with increasing IRES levels, while CP show a significant decrease in LNS as IRES power compensates for the lack of system resilience. 


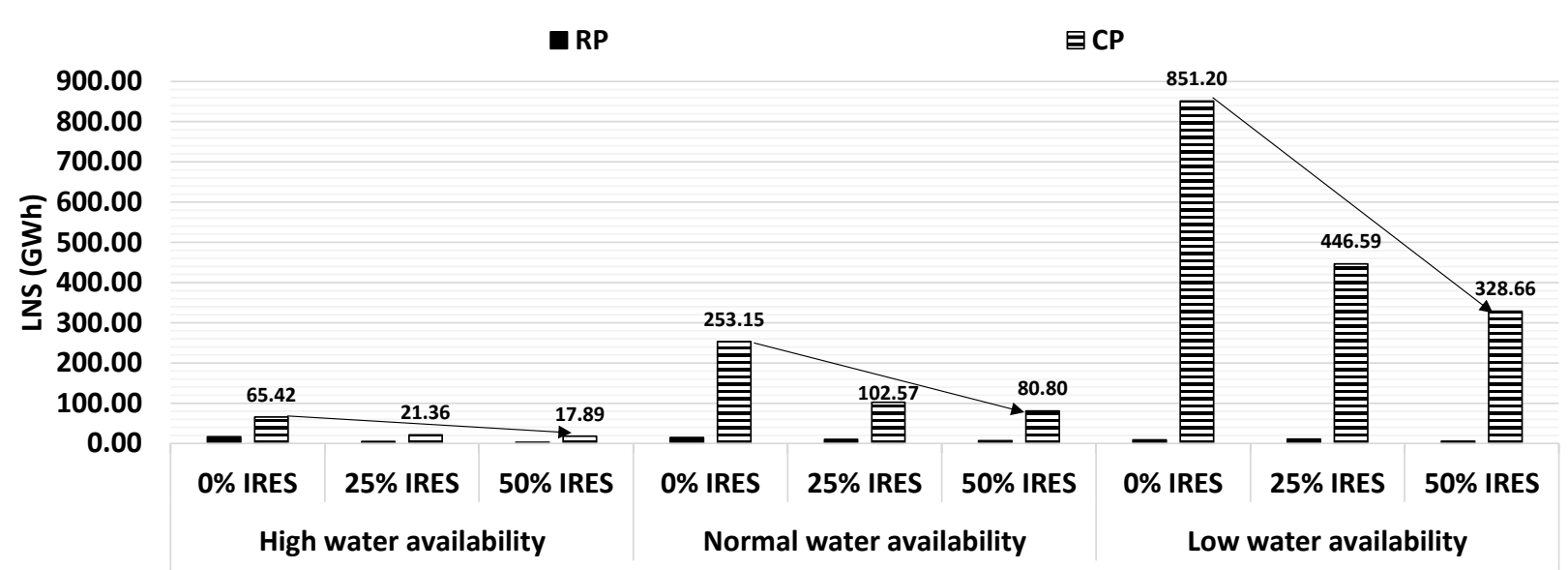

Extreme heat Wave Scenario

Figure 6: Impact of high IRES penetration on LNS during different extreme weather events.

Moreover, it is shown that the increased IRES capacity reduces the gap between RP and $\mathrm{CP}$, in terms of annualized investment and operational costs. For example, the difference in the total annualized investment and operation costs between the RP and CP plans decreases from $+5.70 \%$ to $+1.60 \%$ under the $0 \%$ and $50 \%$ IRES levels respectively, under the "Extreme heat wave - Low water availability" scenario in Table (4). The same trends are also found under the other extreme weather scenarios considered.

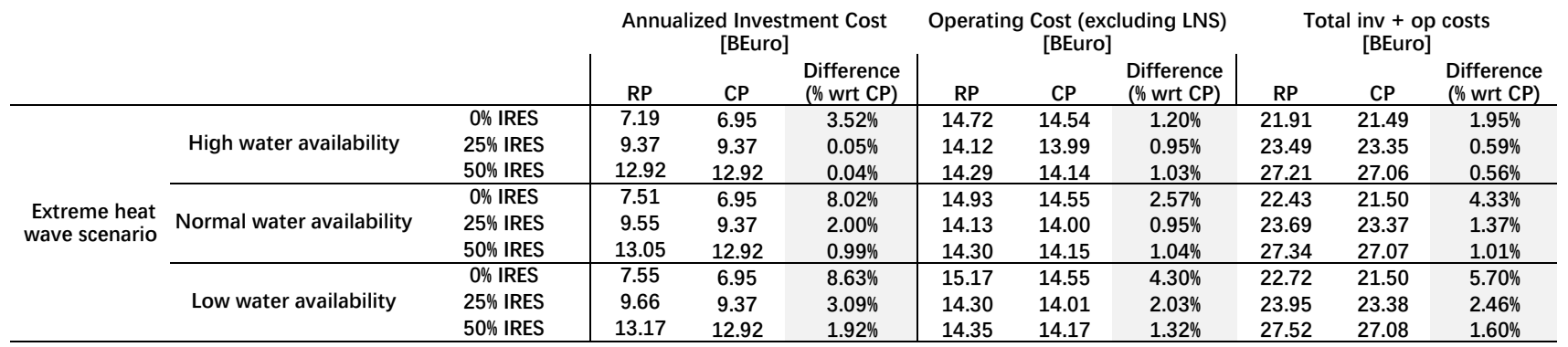

Table 4: Comparison of RP and CP costs under different IRES penetration levels and extreme weather events.

\subsection{Impact of extreme weather events on technology choice and system flexibility}

The previous section has illustrated how power system RP cope with the detrimental impact of extreme weather events, with no significant increase in the system cost. We analyze 
in details the choices in the RP under the different scenarios. Most notably, the generation technology choice and capacity installed are major contributors to the system performance. Figure (7) summarizes the investment capacities and technologies choices under the different extreme weather events and IRES penetration levels. For clarity, the results illustrate the total capacity installed per each cooling technology type (OTC-based capacity vs CLC-based capacity) summed over all thermal power plants installed, under each scenario.

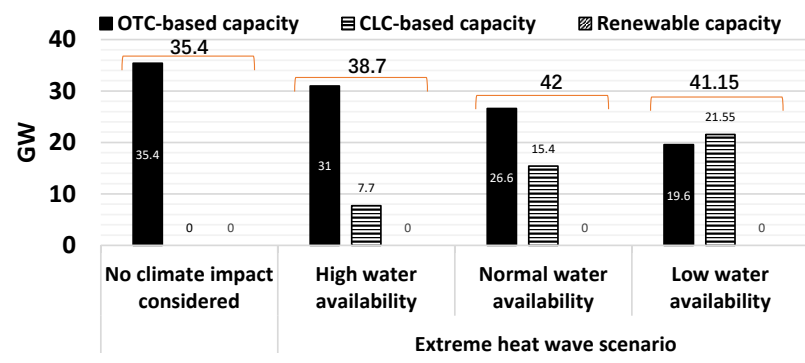

(a) $0 \%$ IRES penetration

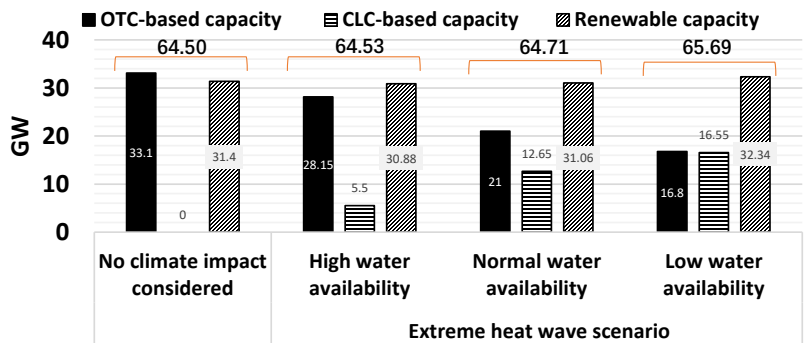

(b) $25 \%$ IRES penetration

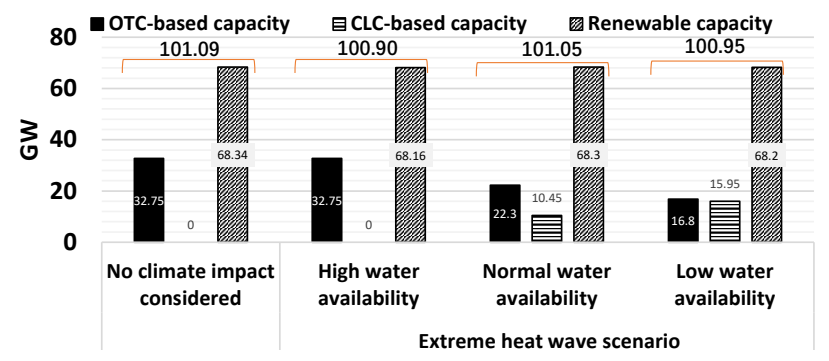

(c) 50\% IRES penetration

Figure 7: RP technology choice and capacity installed under different IRES penetration levels and extreme weather events.

The results show a clear shift from (the cheaper) OTC-based capacities to the (more expensive) CLC-based technology when the heat wave event is accounted for, primarily as a result of internalizing in the system design the impact of the extreme event. This shift to CLC-based units further increases considering lower water availability levels during the heat wave event. The results also show that the total capacity of all technologies installed does not in fact vary in response to different extreme weather events but is rather significantly impacted by the amount of IRES penetration in the system, for an average of $39.3 \mathrm{GW}$, 
64.8GW and 101GW for the 0\%, 25\% and 50\% IRES penetration scenarios, respectively, with low standard deviations of $2.9,0.5$ and 0.08 within each IRES scenario. On the other hand, the significant increase of capacity installed across different IRES penetration scenarios is directly attributed to the increased capacity required to satisfy the operational flexibility needs of the system under these scenarios, as has been discussed in previous work [11].

We finally explore how the operational flexibility of the RP and CP plans are affected by the different extreme climate events. Table (5) summarizes the EFS results at the $99 \%$ confidence level, for all IRES and climate scenarios. It can be seen that when the extreme weather events are not taken into account in the planning phase (as per the CP), the operational flexibility shortage is multiple times that of its RP counterpart under the same extreme weather events. This flexibility shortage difference further increases considering higher levels of IRES penetration. For instance, the EFS reaches approximately $7355 \mathrm{MW}$ for CP compared to $27655 \mathrm{MW}$ for RP, during the extreme weather event for a system with $50 \%$ share of IRES capacity. The flexibility shortages, however, are significantly lower than the load losses for the CP due to the lack of resilience, which were shown to be in the order of several hundred GWh in the previous sections. This is important to note since both RP and $\mathrm{CP}$ accommodate the operational flexibility attribute.

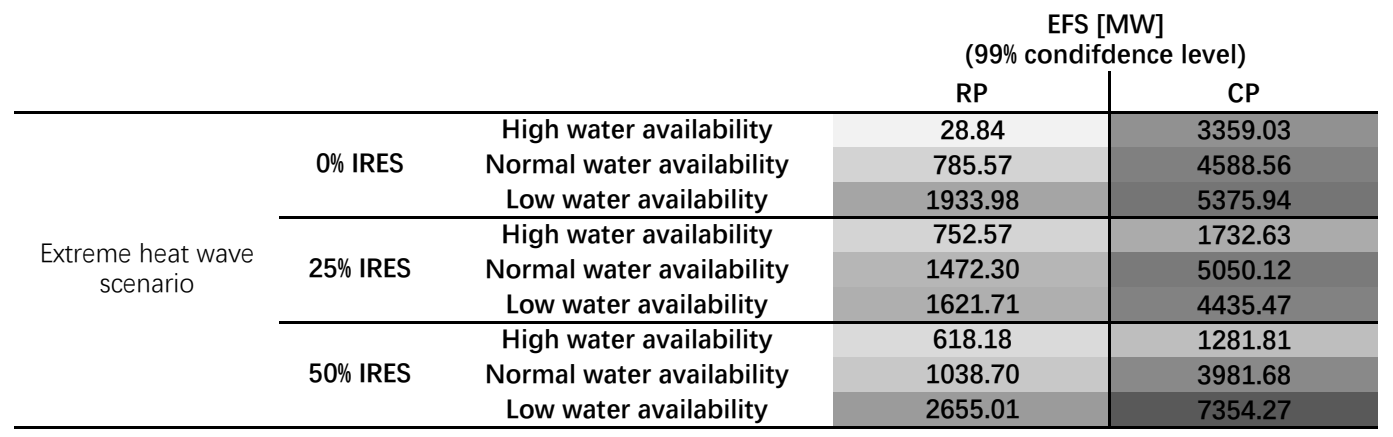

Table 5: Expected Flexibility Shortfall (EFS) of RP under different IRES penetration levels and climate scenarios. 
4.4. Sensitivity of the results for different climate projections (RCP8.5, RCP4.5 and RCP2.6)

In the previous sections, we have shown the improvements achieved by RP which account for extreme heat waves and drought events. Both RP and CP were optimized and/or evaluated under the climate parameters of the $\mathrm{RCP} 8.5$, that is the most pessimistic radiative concentration pathway for the 21st century. In this section, we perform a sensitivity analysis considering other RCP projections from the CMIP5 climate experiments to confirm the relevance of the planning framework proposed under less pessimistic concentration pathways.

RCP 2.6 and 4.5 climate data are used to calculate future power system operating conditions. Most notably, solar irradiance and wind speed data are used to obtain wind and solar-PV CF, and temperature data during the summer period are used to simulate the future heat wave scenarios and their impact on thermal generators. We, then, use the RP and $\mathrm{CP}$ under the RCP 8.5 scenario to check their operational performance under the other RCP scenarios.

Figure (8) shows the performance of the RP and $\mathrm{CP}$ obtained under the RCP 8.5, in terms of LNS during the extreme heat event under all RCP pathways considered. The values shown are the average LNS amounts for all water availability scenarios per each RCP. The results confirm the consistently lower LNS for the RP under all RCP scenarios and for all IRES penetration levels. In addition, as expected, the LNS decreases as less pessimistic RCP scenarios are considered. For example, the average LNS for the RP under 0\% IRES penetration decreases from $10 \mathrm{GWh}$ for the RCP 8.5 to $0.05 \mathrm{GWh}$ for the RCP 2.6 scenarios. 


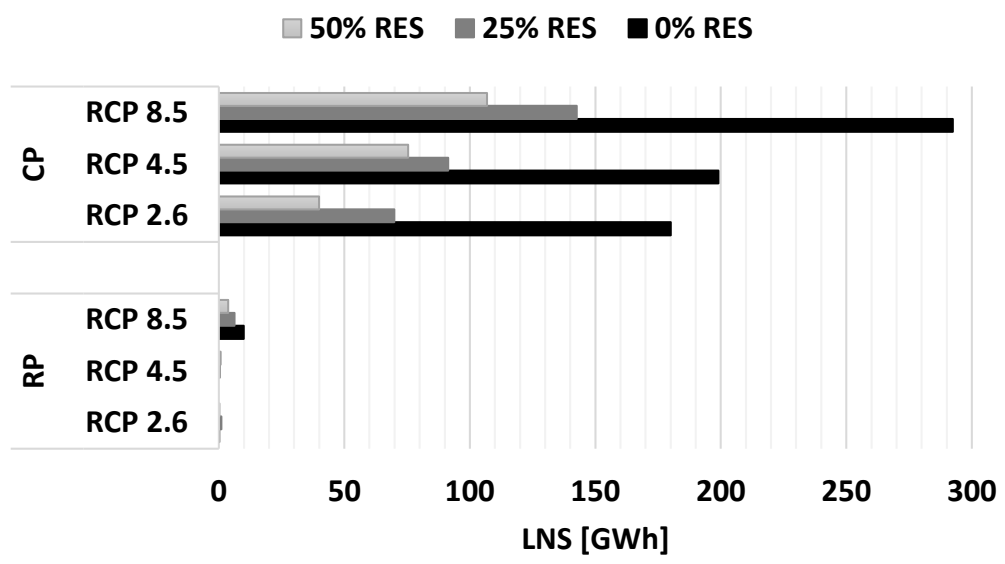

Figure 8: Average amount of LNS under each RCP scenario (8.5, 4.5 and 2.6) and IRES penetration levels (0\%, $25 \%$ and 50\%). Comparison between the results for RP and CP.

With regards to the operational flexibility, the results reported in Figure (9) show the average EFS of the plans obtained under all extreme weather events for different IRES penetration levels. Less obvious trends can be found for the operational flexibility levels of the obtained plans across the different RCPs, as measured by the EFS metric. It can be confirmed, however, that RP consistently outperform CP also in terms of flexibility, as can be seen in the overall lower shortage levels illustrated in Figure (9). The improved flexibility performance of the RP highlights an important interaction between the resilience of the system and its flexibility, and the compound impact of failing to consider either aspect in the power system design phase. 


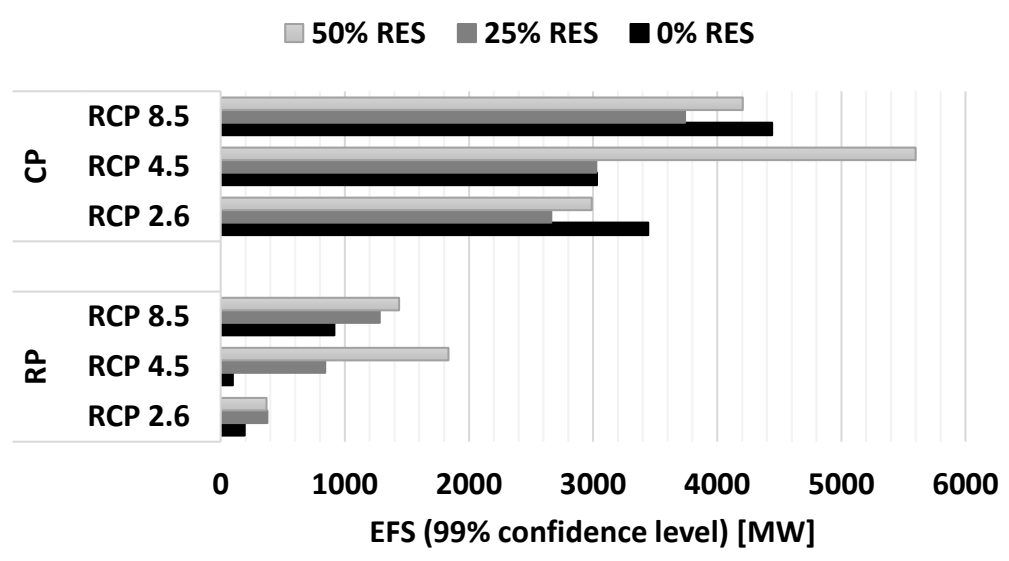

Figure 9: Average amount of EFS under each RCP scenario (8.5, 4.5 and 2.6) and IRES penetration levels $(0 \%, 25 \%$ and $50 \%)$. Comparison between the results for the $\mathrm{RP}$ and $\mathrm{CP}$.

\section{Conclusions}

In this work, we propose a framework for power systems planning considering operational flexibility and resilience against extreme weather events. Specifically, we propose a set of piece-wise linear models to quantify the impact of extreme heat waves and drought events, and propose methods to integrate their impacts within the power system planning models.

We investigate a practically sized case study based on realistic climate projections and system attributes representatives of the southern French geographical area. Several extreme climate scenarios related to heat waves and water shortages are investigated and the results are compared between the resilience-driven planning framework proposed and the conventional planning results.

The results show that significant improvements in terms of load supply during an extreme heat wave and drought events can be achieved under the resilient planning framework compared to conventional planning. It is also shown that although these improvements come at higher investment and operational costs, they are fully offset by the economic savings achieved by reducing the amount of load loss during those events. In terms of system flexibility, the results further show that although the plans obtained have higher flexibility shortage levels, they keep at least an order of magnitude lower than the load losses due 
to the lack of system resilience. This further highlights the advantage of adopting such comprehensive planning framework.

The modeling and optimization framework presented here can be directly extended to multi-regional planning, to account for the differences in weather conditions across the different regions. Moreover, since extreme weather events are uncertain and stochastic in nature, the presented deterministic framework for resilient power system design can be improved by accounting for the uncertainties within a probabilistic framework.

\section{Acknowledgments}

Not applicable

\section{References}

[1] Gianluca Fulli, Marcelo Masera, Catalin Felix Covrig, Francesco Profumo, Ettore Bompard, and Tao Huang. The eu electricity security decision-analytic framework: Status and perspective developments. Energies, 10(4):425, 2017.

[2] MI Alizadeh, M Parsa Moghaddam, N Amjady, P Siano, and MK Sheikh-El-Eslami. Flexibility in future power systems with high renewable penetration: A review. Renewable and Sustainable Energy Reviews, 57:1186-1193, 2016.

[3] Eamonn Lannoye, Damian Flynn, and Mark O'Malley. Evaluation of power system flexibility. IEEE Transactions on Power Systems, 27(2):922-931, 2012.

[4] Juan Ma, Vera Silva, Régine Belhomme, Daniel S Kirschen, and Luis F Ochoa. Evaluating and planning flexibility in sustainable power systems. In Power and Energy Society General Meeting (PES), 2013 IEEE, pages 1-11. IEEE, 2013.

[5] Andreas Ulbig and Göran Andersson. Analyzing operational flexibility of electric power systems. International Journal of Electrical Power 65 Energy Systems, 72:155-164, 2015. 
[6] Jinye Zhao, Tongxin Zheng, and Eugene Litvinov. A unified framework for defining and measuring flexibility in power system. IEEE Transactions on Power Systems, 31 (1):339-347, 2016.

[7] Daniel S Kirschen, Juan Ma, Vera Silva, and Régine Belhomme. Optimizing the flexibility of a portfolio of generating plants to deal with wind generation. In Power and Energy Society General Meeting, 2011 IEEE, pages 1-7. IEEE, 2011.

[8] Nikolaos E Koltsaklis and Michael C Georgiadis. A multi-period, multi-regional generation expansion planning model incorporating unit commitment constraints. Applied energy, 158:310-331, 2015.

[9] Andreas Belderbos and Erik Delarue. Accounting for flexibility in power system planning with renewables. International Journal of Electrical Power $\mathcal{E}$ Energy Systems, 71:33-41, 2015.

[10] Bryan S Palmintier and Mort D Webster. Impact of operational flexibility on electricity generation planning with renewable and carbon targets. IEEE Transactions on Sustainable Energy, 7(2):672-684, 2016.

[11] Islam F Abdin and Enrico Zio. An integrated framework for operational flexibility assessment in multi-period power system planning with renewable energy production. Applied Energy, 222:898-914, 2018.

[12] Yiping Fang and Giovanni Sansavini. Optimizing power system investments and resilience against attacks. Reliability Engineering \& System Safety, 159:161-173, 2017.

[13] Gerald A Meehl and Claudia Tebaldi. More intense, more frequent, and longer lasting heat waves in the 21st century. Science, 305(5686):994-997, 2004.

[14] Selma B Guerreiro, Richard J Dawson, Chris Kilsby, Elizabeth Lewis, and Alistair Ford. Future heat-waves, droughts and floods in 571 european cities. Environmental Research Letters, 13(3):034009, 2018. 
[15] Marc Poumadere, Claire Mays, Sophie Le Mer, and Russell Blong. The 2003 heat wave in france: dangerous climate change here and now. Risk Analysis: an International Journal, 25(6):1483-1494, 2005.

[16] Roberto Rocchetta, Yanfu Li, and Enrico Zio. Risk assessment and risk-cost optimization of distributed power generation systems considering extreme weather conditions. Reliability Engineering \& System Safety, 136:47-61, 2015.

[17] Mathaios Panteli, Cassandra Pickering, Sean Wilkinson, Richard Dawson, and Pierluigi Mancarella. Power system resilience to extreme weather: Fragility modelling, probabilistic impact assessment, and adaptation measures. IEEE Trans. Power Syst, 32: $3747-3757,2017$.

[18] Francesco Cadini, Gian Luca Agliardi, and Enrico Zio. A modeling and simulation framework for the reliability/availability assessment of a power transmission grid subject to cascading failures under extreme weather conditions. Applied energy, 185:267-279, 2017.

[19] Stuart M Cohen, Kristen Averyt, Jordan Macknick, and James Meldrum. Modeling climate-water impacts on electricity sector capacity expansion. In ASME 2014 power conference, pages V002T10A007-V002T10A007. American Society of Mechanical Engineers, 2014.

[20] Chengcheng Shao, Mohammad Shahidehpour, Xifan Wang, Xiuli Wang, and Biyang Wang. Integrated planning of electricity and natural gas transportation systems for enhancing the power grid resilience. IEEE Transactions on Power Systems, 32(6):4418$4429,2017$.

[21] Xinda Ke, Di Wu, Jennie Rice, Michael Kintner-Meyer, and Ning Lu. Quantifying impacts of heat waves on power grid operation. Applied energy, 183:504-512, 2016.

[22] Dirk Rübbelke and Stefan Vögele. Impacts of climate change on european critical 
infrastructures: The case of the power sector. Environmental science \& policy, 14(1): 53-63, 2011.

[23] Yannick Rousseau. Impact of Climate Change on Thermal Power Plants. Case study of thermal power plants in France. PhD thesis, 2013.

[24] Hagen Koch and Stefan Vögele. Dynamic modelling of water demand, water availability and adaptation strategies for power plants to global change. Ecological Economics, 68 (7):2031-2039, 2009.

[25] Omid Mohseni, Heinz G Stefan, and Troy R Erickson. A nonlinear regression model for weekly stream temperatures. Water Resources Research, 34(10):2685-2692, 1998.

[26] Niels Lagergaard Pedersen and Kaj Sand-Jensen. Temperature in lowland danish streams: contemporary patterns, empirical models and future scenarios. Hydrological Processes: An International Journal, 21(3):348-358, 2007.

[27] Jean C Morrill, Roger C Bales, and Martha H Conklin. Estimating stream temperature from air temperature: implications for future water quality. Journal of Environmental Engineering, 131(1):139-146, 2005.

[28] DL Elliot. Adjustment and analysis of data for regional wind energy assessments. In Proceedings of the Workshop on Wind Climate, pages 121-131, 1979.

[29] Isabelle Tobin, Sonia Jerez, Robert Vautard, Françoise Thais, Erik Van Meijgaard, Andreas Prein, Michel Déqué, Sven Kotlarski, Cathrine Fox Maule, Grigory Nikulin, et al. Climate change impacts on the power generation potential of a european midcentury wind farms scenario. Environmental Research Letters, 11(3):034013, 2016.

[30] Isabelle Tobin, Robert Vautard, Irena Balog, François-Marie Bréon, Sonia Jerez, Paolo Michele Ruti, Françoise Thais, Mathieu Vrac, and Pascal Yiou. Assessing climate change impacts on european wind energy from ensembles high-resolution climate projections. Climatic Change, 128(1-2):99-112, 2015. 
[31] Jan Wohland, Mark Reyers, Juliane Weber, and Dirk Witthaut. More homogeneous wind conditions under strong climate change decrease the potential for inter-state balancing of electricity in europe. Earth System Dynamics, 8(4):1047-1060, 2017.

[32] Sonia Jerez, Isabelle Tobin, Robert Vautard, Juan Pedro Montávez, Jose María LópezRomero, Françoise Thais, Blanka Bartok, Ole Bøssing Christensen, Augustin Colette, Michel Déqué, et al. The impact of climate change on photovoltaic power generation in europe. Nature communications, 6:10014, 2015.

[33] F Mavromatakis, G Makrides, G Georghiou, A Pothrakis, Y Franghiadakis, E Drakakis, and E Koudoumas. Modeling the photovoltaic potential of a site. Renewable Energy, 35(7):1387-1390, 2010.

[34] R Chenni, M Makhlouf, T Kerbache, and A Bouzid. A detailed modeling method for photovoltaic cells. Energy, 32(9):1724-1730, 2007.

[35] Laurent Dubus. Monthly and seasonal forecasts in the french power system. In ECMWF Seminar, Personal presentation, 2012.

[36] RTE-France. Available at:. http://clients.rte-france.com, 2017. (Accessed on 20-12-2016).

[37] IEA/NEA. Projected costs of generating electricity 2015 edition. OECD, 2015.

[38] Sami I Attia. The influence of condenser cooling water temperature on the thermal efficiency of a nuclear power plant. Annals of Nuclear Energy, 80:371-378, 2015.

[39] Abigail González-Díaz, Agustín M Alcaráz-Calderón, Maria Ortencia González-Díaz, Ángel Méndez-Aranda, Mathieu Lucquiaud, and Jose Miguel González-Santaló. Effect of the ambient conditions on gas turbine combined cycle power plants with postcombustion co2 capture. Energy, 134:221-233, 2017.

[40] Bryan S Palmintier and Mort D Webster. Heterogeneous unit clustering for efficient operational flexibility modeling. IEEE Trans. Power Syst, 29(3):1089-1098, 2014. 
[41] Fernando J de Sisternes and Mort D Webster. Selection of sample weeks for approximating the net load in generation planning problems. Technical report, ESD Working Paper, Massachusetts Institute of Technology, 2013.

[42] Karl E Taylor, Ronald J Stouffer, and Gerald A Meehl. An overview of cmip5 and the experiment design. Bulletin of the American Meteorological Society, 93(4):485-498, 2012. 